\title{
Industrial Effects of Reducing Greenhouse Gas Emissions: A Case Study of Chemical Material and Product Industry in Taiwan
}

\author{
Yu-Wen Su
}

\begin{abstract}
The goal of Taiwan's Intended Nationally Determined Contributions (INDCs) was to reduce greenhouse gas (GHG) emissions by $20 \%$ and $50 \%$ from 2005 to 2030 and 2050, respectively. This aggregated goal was distributed into industrial level in this study in two steps. First, the industrial GHG emissions from consuming coal, petroleum, gas, and electricity in 27 sectors was calculated. Second, a model connecting economic variables, energy demands, and emissions from 1982 to 2014 was built to analyze the effects of reducing GHG emissions. Emitting the highest GHG in Taiwan, the chemical material and product industry was chosen as a case study. The estimated results indicate that marginal costs of reducing 461,967 ton $\mathrm{CO}_{2}(1.192 \%)$ were decreasing TWD 7,328 million capitals or 22,934 labors, causing the value added decrease by TWD 5,655 million $(1 \%)$ in the chemical material and product industry. In other words, any investments, whose costs are lower than these marginal costs, are worthy to do.
\end{abstract}

Index Terms-Energy consumption, energy price, CES production function, INDCs.

\section{INTRODUCTION}

In the $21^{\text {st }}$ session of the Conference of the Parties (COP21) in 2015 , the main consensus was limiting the global warming to less than 2 degrees Celsius $\left({ }^{\circ} \mathrm{C}\right)$ by 2100 compared to the pre-industrial level. The Earth will warm up by nearly $4^{\circ} \mathrm{C}$, if nothing is done, according to the United Nations Framework Convention on Climate Change (UNFCCC). To achieve the $2{ }^{\circ} \mathrm{C}$ goal, greenhouse gas (GHG) emissions should be reduced by $50 \%$ by 2050 compared to 1990 levels, based on the Intergovernmental Panel on Climate Change (IPCC). Consisting with the above goal, panel countries declared their national climate contributions, Intended Nationally Determined Contributions (INDCs). Even not a contracting party, Taiwan also presented the INDC as the citizen of the Earth. Taiwan's goal is reducing GHG emissions by $20 \%$ and $50 \%$ from 2005 to 2030 and 2050, respectively, in line with the Greenhouse Gas Emission Reduction and Management Act, according to the Executive Yuan of Taiwan.

Taiwan's reduction goal of GHG emissions was top-down. In other words, it was on the macro perspective, and did not consider the economic impacts in individual industries. Distributing the macro reduction goal proportionally to detailed industries may be fair, but not the most effective way, since the energy input structure,

Manuscript received April 10, 2017; revised July 25, 2017.

$\mathrm{Yu}-\mathrm{Wen} \mathrm{Su}$ is with the Industrial Economic and Knowledge Center, Industrial Technology Research Institute, Hsinchu, Taiwan (e-mail: sophieywsu@gmail.com). efficiency, and adjustment elasticity are different among industries. It is also a challenge to customize a reducing goal for each industry. In this study, a systematic method was designed to understand the economic influences of reducing GHG emissions in detailed industries. As the results, the relationship among economic variables, energy demands, and GHG emissions were constructed.

To break down the GHG emissions to 27 industries, the industrial GHG emissions through consuming coal, petroleum, gas, and electricity were calculated, based on the energy consumptions and emission factors from 1982 to 2015. Even though the Taiwan Greenhouse Gas Inventory was published [1], its industrial classifications were too rough. In this report, industrial GHG emissions from consuming electricity were classified into energy sector, considering that electricity suppliers took the responsibility of improving electricity efficiency and reducing GHG emissions. In industrial level, however, it is unreasonable that consuming electricity emits no GHG. As a result, the industrial GHG emissions, including electricity consumption, were recalculated in this study. Some items, which cannot be divided into industrial levels and have small proportions, such as forestry and land use or waste, were not covered in this study.

In addition, the chemical material and products industry, who consumed $16 \%$ of energy in Taiwan, was chosen as a case study to connect the theoretical method and realistic world. Through interviewing key firms in this industry, the estimated results can be checked. The possible industrial paths of reducing GHG emissions were also discussed.

\section{BACKGROUND}

\section{A. Literature Review}

To reduce GHG emissions, the industrial path of influence, through energy consumption and economic activities, needs to be investigated. There are two stages of activity that affect the GHG emissions. First, economic conditions affect industrial energy consumption. Second, different types and amounts of energy consumption produce different amounts of GHG.

In the first stage, economic variables and energy consumption were connected. Two perspectives were considered: production side and demand side. In the production side, most research treated capital, labor and energy as inputs, and studied the relationship among them and how they affected outputs. Moreover, in capital-intensive industries, capital inputs could be the driving forces of energy 
demands. The relationship can be substitute [2]-[4] or complementary [5]-[7]. On the contrary, in labor-intensive industries, energy demands are more likely to be affected by labor inputs. However, little research discussed this topic.

In the demand side, the demand for energy was estimated, and the effects of price and income were often discussed [8]-[13]. The industrial effect in the industrial sector [14]-[17] and service sector [18] were also studied. There are no consensus between production and demand sides. The conflict results may arise because of different datasets, countries' characteristics, and econometric methodologies [19], [20].

For Taiwan, some previous studies supported a causality running from economic growth to energy consumption [21], [22]. Some studies also suggested a bi-directional causality [23], [24]. Later, a causality running from energy consumption to economic growth were also suggested [25], but this relationship existed only when the level of energy consumption is low [26], [27]. Since the energy consumption in Taiwan now is higher than any past records, there is little causality running from energy consumption to economic growth.

In the second stage, energy consumption and GHG emissions were connected. GHG emissions are the results of consuming energy, and different types of energy exhaust different amounts of GHG [28], [29]. This relationship is simply a set of fixed emission factors which is a fixed chemical property of the energy [30]. In Taiwan's case, however, the data of industrial GHG emissions are insufficient.

In this study, a two-stage analysis is proposed. In stage one, the relationship between economic variables and energy demands was studied, shown through arrow (A) in Fig. 1. Capital and labor were the main production factors to determine the output in the production side. Then, the output and exogenous energy prices were used to estimate energy consumption in the demand side. In stage two, the GHG emissions was calculated by energy demands and emission factors, shown by arrow (B) in Fig. 1. All the analysis were at the industrial level. After connecting all the variables, the possible influence path of reducing GHG emissions can be found.

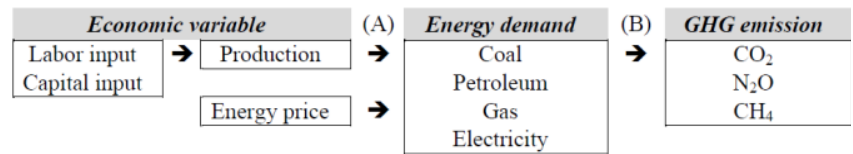

Fig. 1. Analysis structure

\section{B. GHG emissions in Taiwan}

The GHG emissions in Taiwan increased from 73 million tons (MT) to $238 \mathrm{MT}$ carbon dioxide equivalent $\left(\mathrm{CO}_{2} \mathrm{e}\right)$ from 1985 to 2015 , at an annual growth rate of $7.5 \%$. This increasing trend slowed down in recent years. The annually increase rate was $0.5 \%$ between 2005 and 2015. The GHG emissions of different energy consumptions were shown in Fig. 2. The emission mainly come from consuming electricity, which has increased sharply in the past three decades. The emission from petroleum also increased, but dropped slightly in recent years. The emissions from coal and gas both increased smoothly.

The emissions from different energy consumption of detailed industries in Taiwan in 2015 was listed in Table I. Nearly $15.08 \%$ emissions come from petroleum consumption in the transportation sector. $10.15 \%$ and $9.81 \%$ of emissions come from electricity consumption in the electrical and electronic machinery industry and residential sectors, respectively. $7.96 \%$ and $6.85 \%$ of emissions come from electricity and coal consumption, respectively, in the chemical material and product industry. Overall, the chemical material and product industry emitted the highest GHG (16\%). As a result, this industry was chosen as a case study.

TABLE I: GHG EMISSIONS IN TAIWAN IN 2015

\begin{tabular}{|c|c|c|c|c|c|}
\hline$(\%)$ & Coal & Petroleum & Gas & Electricity & Total \\
\hline Agriculture & & 0.46 & & 0.64 & 1.10 \\
\hline Minerals & & 0.05 & 0.00 & 0.11 & 0.15 \\
\hline Process foods, beverages \& tobacco & & 0.27 & 0.01 & 0.87 & 1.16 \\
\hline Textiles, wearing apparel \& accessories & 0.10 & 0.28 & 0.03 & 1.22 & 1.63 \\
\hline Wood \& related products & & 0.01 & & 0.09 & 0.09 \\
\hline Pulp, paper \& printing & 0.58 & 0.06 & 0.02 & 0.84 & 1.49 \\
\hline Coal \& petroleum products & 4.34 & 0.03 & & 0.00 & 4.37 \\
\hline Chemical materials \& products & 6.85 & 0.84 & 0.39 & 7.96 & 16.03 \\
\hline Non-metallic mineral products & 2.16 & 0.35 & 0.19 & 1.22 & 3.92 \\
\hline Basic metal \& related products & 2.83 & 0.40 & 0.35 & 5.05 & 8.63 \\
\hline Electrical \& electronic machinery & & 0.07 & 0.09 & 10.15 & 10.30 \\
\hline Mechanical equipment & & 0.11 & 0.01 & 0.70 & 0.82 \\
\hline Motor vehicles \& Transport equipment & & & & 6.75 & 6.75 \\
\hline Electricity supply & & 0.00 & 0.01 & 3.35 & 3.36 \\
\hline Gas supply & & 0.00 & & 0.10 & 0.10 \\
\hline Water supply \& remediation & & 0.00 & & 0.27 & 0.28 \\
\hline Construction & & 0.07 & & 0.14 & 0.21 \\
\hline Wholesale \& retail trade & & & & 1.15 & 1.15 \\
\hline Accommodation \& food services & & 0.53 & 0.63 & 0.67 & 1.83 \\
\hline Communication, telecommunication \& information services & & 0.01 & & 0.31 & 0.32 \\
\hline Finance, insurance \& real estate services & & 0.01 & 0.00 & 0.22 & 0.23 \\
\hline Professional, scientific \& technical services & & & & 0.32 & 0.32 \\
\hline Public administration services & & 0.50 & 0.01 & 1.33 & 1.83 \\
\hline Education, health, social work \& entertainment services & & & & 1.92 & 1.92 \\
\hline Other services & & 0.19 & 0.00 & 4.16 & 4.35 \\
\hline Transportation & & 15.08 & & 0.79 & 15.87 \\
\hline Residential sector & & 1.25 & 0.72 & 9.81 & 11.78 \\
\hline Total & 16.85 & 20.56 & 2.45 & 60.14 & 100.00 \\
\hline
\end{tabular}




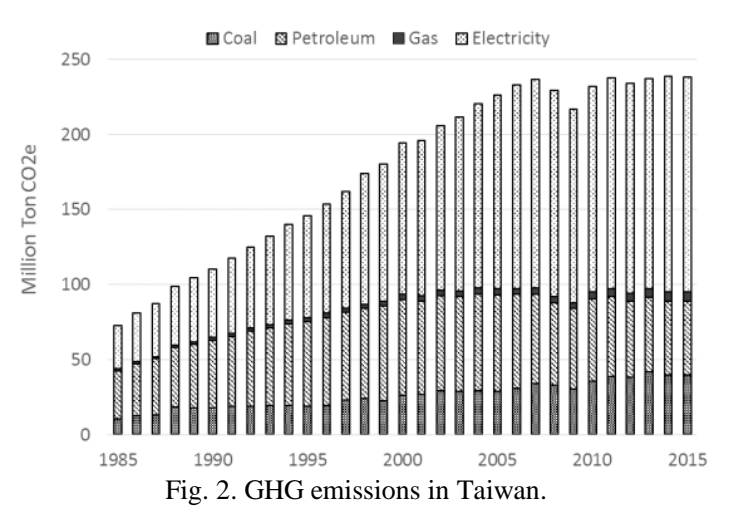

\section{Methodology}

The Economy, Energy, and Emission (EEE) model of Taiwan was constructed to find the industrial target of reducing GHG emissions. There were two estimations: energy demand and GHG emission.

\section{A. Economic Variables and Energy Demands}

The first part of the EEE model was estimating demands for four generic energy sources: coal, petroleum, gas, and electricity. The demand function for a specific industry was expressed as

$$
\ln Q_{e}=\alpha(t)+\beta \ln P_{e}+\gamma \ln Y
$$

where $Q_{e}$ was the quantity of energy demand and $e=$ (coal, petroleum, gas, electricity), $P_{e}$ was the price of energy $e$, and $Y$ was the production which also represented the income. There were 57 energy resources in Energy Balance Sheets (EBS), such as coking coal or fuel oil. We grouped these energy resources, and estimated the demand for four generic energy. Under the Cobb-Douglas function, parameters $\alpha(t)$ represented a technical progress factor, and $\alpha(t)=\alpha_{1} t+\alpha_{2} t^{2}$ where $t$ was a time trend. The marginal effect of price and income were

$$
\frac{\partial Q_{e}}{\partial P_{e}}=\beta \frac{Q_{e}}{P_{e}} \text { and } \frac{\partial Q_{e}}{\partial Y}=\gamma \frac{Q_{e}}{Y}
$$

Production $Y$ in (1) was determined by two production factors: capital $(K)$ and labor $(L)$. A constant electricity of substitution (CES) production function was used. This function allowed different degrees of substitution between $K$ and $L$ in different industries. The CES production function was expressed as

$$
Y=c\left[a K^{b}+(1-a) L^{b}\right]^{\frac{1}{b}}
$$

where $0<a<1$ was the share parameter, $b$ determined the degree of substitutability of inputs, the elasticity of substitution was $1 /(1-b)$, and $c$ was the factor productivity. The marginal product of capital (MPK) and marginal product of labor (MPL) were

$$
\text { MPK }=\frac{\partial Y}{\partial K}=a\left(\frac{Y}{K}\right)^{1-b}, \mathrm{MPL}=\frac{\partial Y}{\partial K}=(1-a)\left(\frac{Y}{L}\right)^{1-b} .
$$

The causality run from production to energy consumption in one direction. The relationship between production factors and energy was analyzed through a mediator, production. All functions were estimated using econometric computer

\section{program Stata.}

\section{B. Energy Demands and GHG Emissions}

The second part of the EEE model was calculating GHG emissions $\left(E_{e}\right)$ through multiply the quantity of energy demand $\left(Q_{e}\right)$ in calorific value by the emission factor $\left(F_{e}\right)$ for that energy. The GHG emission of generic energy $e$ was also the summation of GHG emissions of detailed energy $k$ ( $k=$ $1 \ldots K)$. The equation was expressed as

$$
E_{e}=Q_{e} F_{e}=\sum_{k=1}^{K} q_{e, k} f_{e, k}
$$

where $q_{e, k}$ was the consumption of detailed energy $k$ in calorific value,

$$
Q_{e}=\sum_{k=1}^{K} q_{e, k}
$$

and $f_{e, k}$ was the emission factor of detailed energy $k$. The $q_{e, k}$ and $f_{e, k}$ were known, so the generic emission factor was calculated as

$$
F_{e}=\sum_{k=1}^{K} \frac{q_{e, k}}{Q_{e}} f_{e, k}=\sum_{k=1}^{K} r_{e, k} f_{e, k}
$$

where $r_{e, k}$ represented the consumption ratio of detailed energy $k$ over the generic energy. The generic emission factor was the weighted average of detailed emission factors. This emission factor took into account the specific mix of energy in each industry and varies over time. Modelled emissions were also guaranteed to match actual emissions, since emission factors were calculated from actual energy consumptions. By (5), the marginal effect of energy demand on GHG emissions was simply expressed as

$$
\frac{\partial E_{e}}{\partial Q_{e}}=F_{e}
$$

\section{Factors of Reducing GHG Emissions}

The main driving forces of GHG emission were energy price and production, and production was determined by capital and labor inputs. For the most conservative case, technical progress and productivity were assumed to be fixed. Based on (2), (4) and (8), the marginal effects of energy price, production, capital and labor on GHG emissions were calculated simply by the chain rule

$$
\begin{aligned}
& \frac{\partial E_{e}}{\partial P_{e}}=\frac{\partial E_{e}}{\partial Q_{e}} \frac{\partial Q_{e}}{\partial P_{e}}, \quad \frac{\partial E_{e}}{\partial Y}=\frac{\partial E_{e}}{\partial Q_{e}} \frac{\partial Q_{e}}{\partial Y}, \\
& \frac{\partial E_{e}}{\partial K}=\frac{\partial E_{e}}{\partial Q_{e}} \frac{\partial Q_{e}}{\partial Y} \frac{\partial Y}{\partial K}, \frac{\partial E_{e}}{\partial L}=\frac{\partial E_{e}}{\partial Q_{e}} \frac{\partial Q_{e}}{\partial Y} \frac{\partial Y}{\partial L} .
\end{aligned}
$$

\section{Data}

Three different data sets were considered. First, gross fixed capital formation, depreciation, employed people, and gross value added came from the Directorate General of Budget, Accounting and Statistics (DGBAS) of Taiwan. Capital input was measured by the cumulated gross fixed capital formation minus depreciation. Labor input was measured by the employed people. Output was measured by the gross value added. Second, consumptions of coal, petroleum, gas, and electricity came from the EBS in calorific value $\left(10^{7} \mathrm{kcal}\right)$. Third, GHG emission were calculated through multiply the 
four generic energy consumption by the emission factor for that energy. The emission factor is a fixed chemical property of the energy, based on IPCC (2006).

Energy prices were collected additionally. Price of coal was measured by the price of the United States industrial coking coal (TWD/tonne). Price of petroleum was measured by the price of west Texas intermediate crude oil (TWD/barrel). Price of gas was measured by the price of right-of-way natural gas $\left(\mathrm{TWD} / \mathrm{m}^{3}\right)$ of the Chinese Petroleum Cooperation. Price of electricity (TWD/kWh) came from the TaiPower Company. All prices were adjusted by price indexes to remove the influence of inflation. The time span was from 1982 to 2014.

Most of industries in EBS can easily find corresponding industries of the DGBAS, except the energy sector. The items of energy sector were reclassified to appropriate industries shown in Table II.

\begin{tabular}{|c|c|}
\hline $\begin{array}{c}\text { Energy Balance Sheet } \\
\text { (Energy sector) }\end{array}$ & $\begin{array}{l}\text { National Account } \\
\text { (Industrial sector) }\end{array}$ \\
\hline $\begin{array}{l}\text { - Coal mines } \\
\text { - Oil and gas extraction }\end{array}$ & - Minerals \\
\hline $\begin{array}{ll}- & \text { Coke ovens } \\
\text { - } & \text { Blast Furnaces } \\
\text { - } & \text { Petroleum refineries } \\
\end{array}$ & - Coal \& petroleum products \\
\hline $\begin{array}{ll}\text { - } & \text { Electricity plants } \\
\text { - } & \text { Electricity to pump up } \\
\text { - } & \text { Cogeneration plants }\end{array}$ & - Electricity supply \\
\hline - Gas companies & - Gas supply \\
\hline
\end{tabular}

\section{CASe Study: Chemical Materials AND Products}

\section{A. Current Situation}

The chemical material and product industry, consumed $16 \%$ of energy and emitted $16 \%$ of GHG in 2015 , was the largest GHG-emitting industry in Taiwan. The GHG emissions in chemical material and product industry rose from $9 \mathrm{MT}$ to $38 \mathrm{MT} \mathrm{CO}_{2} \mathrm{e}$ between 1985 and 2015, in an annual growth rate of $11 \%$, shown in Fig. 3. Separating into different energy resources, the annual growth rate was $43 \%,-1 \%, 41 \%$ and $12 \%$ for coal, petroleum, gas and electricity, respectively, while related proportion in 2015 was $43 \%, 5 \%, 2 \%$ and 50\%, respectively. In other words, coal consumption was the main driving force of the increasing trend in Fig. 3, while the electricity consumption increased proportionally to the total. Petroleum consumption was one of the main GHG-emitting sources in 1990s, but decreased in the late years. Gas consumption emitted the least GHG but increased rapidly.

The chemical material and product industry played an important role in Taiwan's economy growth for the past decades. Its real value added was TWD 566 billion, contributing to 4\% of Taiwan's GDP; it also created 311,260 job opportunities and invested TWD 215 billion in 2014, based on the DGBAS. Nearly two fifth of production were exported, mainly to China, Southeast Asia, Japan, and the U.S The export in 2014 was TWD 1,408 billion according to the Finance Ministry of Taiwan, while production was TWD 3,486 billion based on DGBAS. In other words, it may be not a contradiction between reducing GHG emissions and satisfying domestic demands of chemical materials and products. However, reducing GHG emissions may cause some economic impact in the chemical material and product industry, as well as the whole economy. The marginal effects were estimated in this study to understand the potential influence of Taiwan's INDC. As the results, the government and industry can prepare for it.

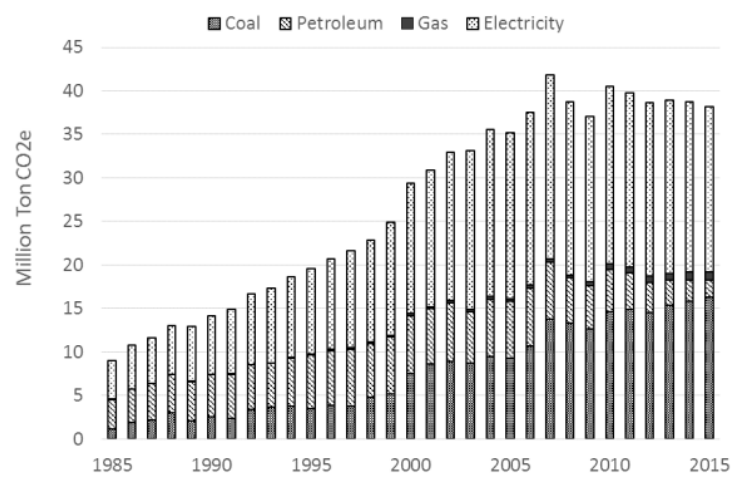

Fig. 3. GHG emissions in chemical materials and products industry.

\section{B. Estimated Results}

The estimated results of the CES production function in the chemical material and product industry were listed in Table III. The MPK and MPL were 0.247 and 0.773 , respectively. In other words, investing one million will increase production by TWD 247,000, and the output per labor was TWD 773,000. In addition, the elasticity of substitution was 2.766 .

TABLE III: ESTIMATED RESULTS OF CES PRODUCTION FUNCTION

\begin{tabular}{lrcr}
\hline & Coefficient & (Robust S.D.) & \\
\hline$c$ & 0.7105 & $(0.0152)$ & $* * *$ \\
$a$ & 0.3783 & $(0.0182)$ & $* * *$ \\
$b$ & 0.6385 & $(0.1229)$ & $* * *$ \\
Adjust $R^{2}$ & 0.9964 & & \\
$n$ & 33 & & \\
*** denotes significance at the 1\% statistical level.
\end{tabular}

The estimated results of demand for four generic energy were shown in Table IV. The price elasticities were -0.398 and -1.307 for coal and gas demands, following the law of demand. The range of use is wider for coal than that for gas in this industry, and the unit price is relatively lower for coal than that for gas. Thus, the demand was more elastic to gas price than coal price. However, the price elasticity of petroleum demand was 1.143 , which was positive. Petroleum products were also the main outputs in the chemical material and product industry. Thus, higher prices mean higher revenues which increased the demand quantity of petroleum raw materials. The price elasticity of electricity demand was zero because electricity inputs were hardly substituted by other fuels, and the real electricity prices in Taiwan were quite low in the past decades.

The income (production) elasticity were all significantly positive for four generic energy, which were $1.375,0.357$, 1.307, and 1.143 for coal, petroleum, gas, and electricity demands, respectively. In other words, production, measured by value added, were the driving force of energy demands. However, this effect for petroleum demand was inelastic. For the chemical material and product industry, petroleum was mainly raw materials, while other energy resources were used as fuels.

The weighted emission factors of four generic energy in the chemical material and product industry were shown in Table $\mathrm{V}$. When consuming same amount energy in calorific value 
$\left(10^{7} \mathrm{kcal}\right)$, the electricity consumption emitted highest carbon dioxide, followed by the coal and petroleum consumption. The gas consumption, emitted the least, was the cleanest fossil fuel for this industry. Because of different energy combinations, these factors varied over time, Table V listed the latest year of 2014 .

TABLE IV: ESTIMATED RESULTS OF ENERGY DEMAND

\begin{tabular}{|c|c|c|c|c|}
\hline & Coal & Petroleum & Gas & Electricity \\
\hline$\beta$ & $\begin{array}{l}-0.3976 \text { ** } \\
(0.1481)\end{array}$ & $\begin{array}{l}1.1430 \text { *** } \\
(0.1799)\end{array}$ & $\begin{array}{l}-1.5695 * * * \\
(0.3151)\end{array}$ & \\
\hline$\gamma$ & $\begin{array}{l}1.3754 \text { *** } \\
(0.1126)\end{array}$ & $\begin{array}{l}0.3571 \text { *** } \\
(0.1304)\end{array}$ & $\begin{array}{l}1.3072 \text { *** } \\
(0.0767)\end{array}$ & $\begin{array}{l}1.1434 \text { *** } \\
(0.0020)\end{array}$ \\
\hline$\alpha_{2}$ & $\begin{array}{r}0.0162 \text { ** } \\
(0.0072)\end{array}$ & $\begin{array}{l}0.0730 * * * \\
(0.0160) \\
-0.0022 * * * \\
(0.0004)\end{array}$ & & \\
\hline$R^{2}$ & 0.9999 & 0.9999 & 0.9948 & 0.9999 \\
\hline$n$ & 33 & 33 & 33 & 33 \\
\hline
\end{tabular}

TABLE V: EMISSION FACTORS (2014)

\begin{tabular}{rc}
\hline & Emission factor (ton CO2 /107 kcal) \\
\hline Coal & 4.010 \\
Petroleum & 3.100 \\
Gas & 2.351 \\
Electricity & 6.058 \\
\hline
\end{tabular}

It should be noticed that there are limitations in this analysis. First, coal, petroleum, gas, and electricity are not substitutes. They are demanded independently based on production and energy prices. Considering the production processes cannot be switched arbitrarily in the short term, this setting is acceptable. Second, energy prices are exogenous. This setting is reasonable because Taiwan, as a price taker, is a small market and has little bargaining power for prices of imported fuels. For electricity, the price is given by the natural monopolistic electric utility, Taipower. However, Taiwan's real electricity prices fluctuated slightly in the past decades. Having no effect on energy demands now does not mean it will have no effect in the future when electricity prices change dramatically.

\section{Policy Implications}

Based on the estimated results, there were two driving forces of GHG emissions: production and energy prices. Decreasing production by $1 \%$ will reduce $\mathrm{GHG}$ emissions by $1.192 \%$, nearly 461,967 ton $\mathrm{CO}_{2}$. This $1 \%$ decrease of production was the result of diminishing 22,934 job opportunities or disinvesting TWD 7,328 million in the chemical material and product industry. On the other hand, increasing the prices of coal and gas by $1 \%$ will reduce GHG emissions by $0.163 \%$ and $0.036 \%$, relatively. On the contrary, increasing the price of petroleum by $1 \%$, GHG emissions will rise by $0.072 \%$. Electricity prices will not affect $\mathrm{GHG}$ emissions. Overall, the influence of production is higher than that of energy prices. The path of marginal influence was drawn in Fig. 4.

Now we go back to Taiwan's INDC: reducing GHG emissions by $20 \%$ from 2005 to 2030 . If the chemical material and product industry reaches this goal, one of the feasible schemes is reducing production by $17 \%^{1}$, nearly TWD 96

\footnotetext{
${ }^{1}$ Based on the estimated results, decreasing production by $1 \%$ will reduce GHG emissions by $1.192 \%$. Thus, to reduce GHG emissions by $20 \%$, the production should decrease by $17 \%(=20 / 1.192)$.
}

billion. This reduction can be implemented through disinvesting TWD 122,953 million, and every TWD $0.32^{2}$ million capital can be substituted for one labor at the same production. This is also the potential costs of reducing GHG emissions.

Reducing GHG emissions is inevitable worldwide. Since the possible effects are known, the role of government is to make sure that the transforming process runs smoothly. When the chemical material and product industry scales down, structural unemployment and idle assets need to be intervened by the government. The government should, for example, supervise the lay-off policy of companies and provide a social safety net. The government also should lead the innovation of improving energy efficiency.

\section{CONCLUSION}

To reduce GHG emissions in Taiwan, the effects among labor, capital, production, energy demands, and GHG emissions were econometrically analyzed in this study. Emphases were placed on calculating industrial GHG emissions, and evaluating potential costs of GHG reduction.

Industrial GHG emissions were calculated through multiply the four generic energy consumption by the emission factor for that energy. This calculation included industrial GHG emissions from consuming electricity, which was originally counted in the energy sector but not in the individual industries. This dataset covers GHG emissions from consuming coal, petroleum, gas and electricity in 27 industries/sectors in Taiwan between 1982 and 2014.

As the largest GHG-emitting industry in Taiwan, the chemical material and product industry was chosen as a case study. The marginal effects of reducing GHG emissions were estimated. Estimated results indicated that decreasing production by $1 \%$ will reduce GHG emissions by $1.192 \%$. This decrease of production was caused by diminishing 22,934 job opportunity or TWD 7,328 million capitals, or their combination with a ratio of TWD 0.32 million capital to one labor. On the other hand, increasing the price of coal and gas by $1 \%$ will reduce GHG emissions by $0.163 \%$ and $0.036 \%$ relatively. Increasing petroleum price by $1 \%$ will, contrarily, raise GHG emissions by $0.072 \%$, because petroleum products were a source of revenue in the chemical material and product industry. In addition, electricity prices had no effect on GHG emissions.

Further research into other industries in Taiwan will provide a more complete picture of the industrial influence of reducing GHG emissions. At the current situation, all the effects were intra-industrial (direct effects). Inter-industrial effects can be further studied considering the upstream and downstream of the industrial chain (indirect effects). Considering both direct and indirect effects, the aggregated effects will be more accurate. This analysis can also be applied to other countries or regions.

\footnotetext{
2 Marginal Rate of Technical Substitution $($ MRTS) $=$ MPK/MPL = $0.247 / 0.773=0.32$.
} 


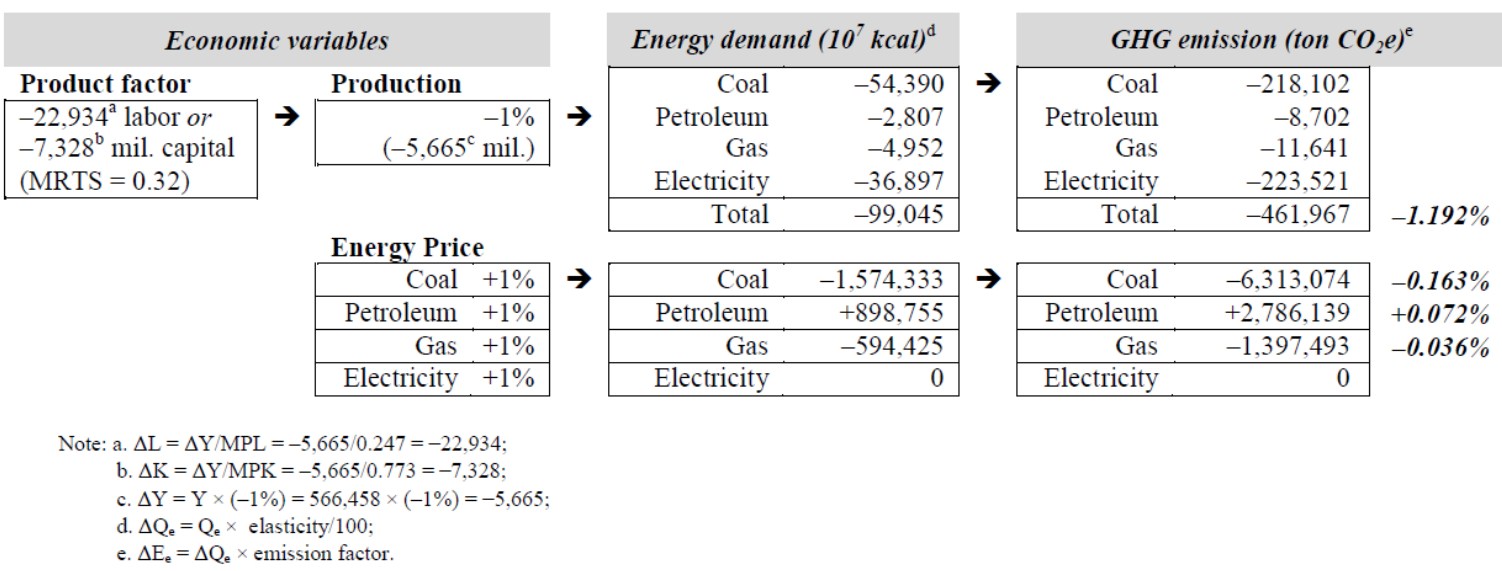

Fig. 4. Influence path of reducing GHG emissions.

\section{ACKNOWLEDGMENT}

I would like to express my sincere gratitude to $\mathrm{Mr}$. Chih-Chung Liu, Dr. Keh-Ming Horng, Mr. Chen-Lu Chang, and Mr. Ping-Shuo Hsu for practical advices from the viewpoint of firms. All remaining errors are my own.

\section{REFERENCES}

[1] Environmental Protection Administration, "2015 Taiwan Greenhouse Gas Inventory," Environmental Protection Administration, 2016.

[2] K.-P. Chang, "Capital-energy substitution and the multi-level CES production function," Energy Econ., vol. 16, no. 1, pp. 22-26, Jan. 1994.

[3] M. J. Koetse, H. L. F. de Groot, and R. J. G. M. Florax, “Capital-energy substitution and shifts in factor demand: A meta-analysis," Energy Econ., vol. 30, no. 5, pp. 2236-2251, Sep. 2008.

[4] P. Thompson and T. G. Taylor, "The capital-energy substitutability debate: A new look," Rev. Econ. Stat., vol. 77, no. 3, pp. 565-569, 1995.

[5] B. E. Apostolakis, "Energy - capital substitutability/ complementarity," Energy Econ., vol. 12, no. 1, pp. 48-58, Jan. 1990.

[6] E. R. Berndt and D. O. Wood, "Engineering and econometric interpretations of energy-capital complementarity," Am. Econ. Rev., vol. 69 , no. 3, pp. 342-354, 1979.

[7] J. L. Solow, "The capital-energy complementarity debate revisited," Am. Econ. Rev., vol. 77, no. 4, pp. 605-614, 1987.

[8] A. R. F. Al-Faris, "The demand for electricity in the GCC countries," Energy Policy, vol. 30, no. 2, pp. 117-124, 2002.

[9] H. A. Amarawickrama and L. C. Hunt, "Electricity demand for Sri Lanka: a time series analysis," Energy, vol. 33, no. 5, pp. 724-739, 2008.

[10] Z. Atakhanova and P. Howie, "Electricity demand in Kazakhstan," Energy Policy, vol. 35, no. 7, pp. 3729-3743, 2007.

[11] V. Bianco, O. Manca, S. Nardini, and A. A. Minea, "Analysis and forecasting of nonresidential electricity consumption in Romania," Appl. Energy, vol. 87, no. 11, pp. 3584-3590, 2010.

[12] S. Fan and R. J. Hyndman, "The price elasticity of electricity demand in South Australia," Energy Policy, vol. 39, no. 6, pp. 3709-3719, 2011.

[13] M. G. Lijesen, "The real-time price elasticity of electricity," Energy Econ., vol. 29, no. 2, pp. 249-258, 2007.

[14] T. B. Bjørner and H. H. Jensen, "Energy taxes, voluntary agreements and investment subsidies - A micro-panel analysis of the effect on Danish industrial companies' energy demand," Resour. Energy Econ., vol. 24, no. 3, pp. 229-249, 2002.

[15] Z. Dilaver and L. C. Hunt, "Industrial electricity demand for Turkey: a structural time series analysis," Energy Econ., vol. 33, no. 3, pp. 426-436, 2011

[16] J. Roy, A. H. Sanstad, J. A. Sathaye, and R. Khaddaria, "Substitution and price elasticity estimates using inter-country pooled data in a translog cost model," Energy Econ., vol. 28, no. 5, pp. 706-719, 2006.
[17] G. Urga and C. Walters, "Dynamic translog and linear logit models: A factor demand analysis of interfuel substitution in US industrial energy demand," Energy Econ., vol. 25, no. 1, pp. 1-21, 2003.

[18] K.-M. Lim, S.-Y. Lim, and S.-H. Yoo, "Short-and long-run elasticities of electricity demand in the Korean service sector," Energy Policy, vol. 67, pp. 517-521, 2014.

[19] C.-C. Lee and C.-P. Chang, "Energy consumption and economic growth in Asian economies: A more comprehensive analysis using panel data," Resour. Energy Econ., vol. 30, no. 1, pp. 50-65, Jan. 2008.

[20] I. Ozturk, "A literature survey on energy-growth nexus," Energy Policy, vol. 38 , no. 1, pp. 340-349, Jan. 2010.

[21] B. S. Cheng and T. W. Lai, "An investigation of co-integration and causality between energy consumption and economic activity in Taiwan," Energy Econ., vol. 19, no. 4, pp. 435-444, Oct. 1997.

[22] P. Holtedahl and F. L. Joutz, "Residential electricity demand in Taiwan," Energy Econ., vol. 26, no. 2, pp. 201-224, 2004.

[23] A. M. M. Masih and R. Masih, "On the temporal causal relationship between energy consumption, real income, and prices: Some new evidence from Asian-energy dependent NICs based on a multivariate cointegration/vector error-correction approach," J. Policy Model., vol 19, no. 4, pp. 417-440, 1997.

[24] H.-Y. Yang, "A note on the causal relationship between energy and GDP in Taiwan," Energy Econ., vol. 22, no. 3, pp. 309-317, Jun. 2000.

[25] C.-C. Lee and C.-P. Chang, "Structural breaks, energy consumption, and economic growth revisited: Evidence from Taiwan," Energy Econ., vol. 27 , no. 6 , pp. 857-872, Nov. 2005.

[26] J.-L. Hu and C.-H. Lin, "Disaggregated energy consumption and GDP in Taiwan: A threshold co-integration analysis," Energy Econ., vol. 30 no. 5, pp. 2342-2358, Sep. 2008.

[27] C.-C. Lee and C.-P. Chang, "The impact of energy consumption on economic growth: Evidence from linear and nonlinear models in Taiwan," Energy, vol. 32, no. 12, pp. 2282-2294, Dec. 2007.

[28] R. N. E. Huaman and T. X. Jun, "Energy related $\mathrm{CO}_{2}$ emissions and the progress on CCS projects: A review," Renew. Sustain. Energy Rev., vol. 31, pp. 368-385, Mar. 2014.

[29] T. A. Napp, A. Gambhir, T. P. Hills, N. Florin, and P. S. Fennell, “A review of the technologies, economics and policy instruments for decarbonising energy-intensive manufacturing industries," Renew. Sustain. Energy Rev., vol. 30, pp. 616-640, Feb. 2014.

[30] IPCC, 2006 IPCC Guidelines for National Greenhouse Gas Inventories, Intergovernmental Panel on Climate Change, 2006.

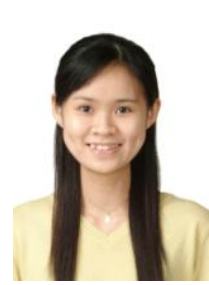

Yu-Wen Su was born in Taiwan in 1983. She received the $\mathrm{PhD}$ degree in economics from National Taiwan University, Taipei, Taiwan in 2013. Dr. Su currently is an researcher in Industrial Technology Research Institute, Hsinchu, Taiwan. Her research interests include applied microeconometrics, time series analysis, input-output analysis, and energy economics. 